\title{
Shielding effect of reinforced concrete fences in electromagnetic fields of industrial frequency
}

\author{
Mariya Amirkhanyan ${ }^{1}$, Fedor Bryukhan ${ }^{2, *}$ \\ ${ }^{1}$ NPO Gidrotehproekt, Oktyabr'skaya str. 55A, 175400 Valday City, Novgorod Region, Russia \\ ${ }^{2}$ Moscow State University of Civil Engineering, Yaroslavskoe shosse, 26, Moscow, 129337, Russia
}

\begin{abstract}
Electromagnetic fields (EMF) are one of the main types of physical pollution of the environment in urban lands. The danger of adverse impact of EMF on human health increases with growth of electric power consumption. Therefore, the issues of protection of the population against EMF impact are becoming very important. One of the options for protection against EMF exposure is the use of reinforced concrete fences with shielding properties. Despite the simplicity of such a device against EMF, it can be stated that shielding effect assessment issues are poorly known. The objective of this paper is to assess the shielding effect of reinforced concrete fences in EMF industrial frequency. The shielding effect of the reinforced concrete fences study was conducted on the surrounding area of the thermal power plant (TPP), located on the edge of Mytishchi city of the Moscow Region. The effects of an abrupt increase in the EMF intensity in front of the reinforced concrete fence and its decrease behind the fence are revealed. It is found that these effects are associated with the concrete reinforcement impact inside the fence, in which an alternating electric current is generated. The shielding effect determines the partial reflection of EMF in front of the fence and decrease of EMF inside it. Accounting for the shielding effect of reinforced concrete fences provides perspectives of organizing the protection of the population near residential and industrial buildings, as well as protection of personnel working in the strong EMF areas.
\end{abstract}

\section{Introduction}

It is common knowledge that electromagnetic fields (EMF) of industrial frequency are one of the main types of physical pollution of the environment in urban areas $[1,2]$. With the increase of electric power consumption, the level of electromagnetic pollution of settlements and industrial areas increases as well, causing growing public concern. This concern is escalating due to the fact that EMF is insensible to human sense organs and the intensity of EMF can only be determined using instrumental measurements.

As a result of these circumstances, the issues of a person protection from the negative impact of EMF and identification of areas with low EMF intensity both in residential and industrial areas are of great interest. One of the potential facilities that protect people from

\footnotetext{
* Corresponding author: pniiis-gip@ mail.ru
} 
the impact of EMF are reinforced concrete fences. This article is dedicated to the assessment of the shielding effect of such fences in EMF industrial frequency. It should be noted that despite the simplicity of this method of protection from EMF exposure, this issue has not been studied into the matter. Only a small number of papers on the shielding effect of reinforced concrete fences can be mentioned, for example, [3, 4].

\section{Methodology}

In order to undertake the study, we used an Octave-110A device with P6-70 and P6-71 antennas for magnetic (P6-70) and electric (P6-71) fields measurements. The measurements taken with this device exclude an air temperature below $+5{ }^{\circ} \mathrm{C}$ and above $+40{ }^{\circ} \mathrm{C}$, air humidity above $90 \%$ and atmospheric precipitations. Measurement results records and transfer of data to a personal computer are carried out using a special built-in program Signal-plus.
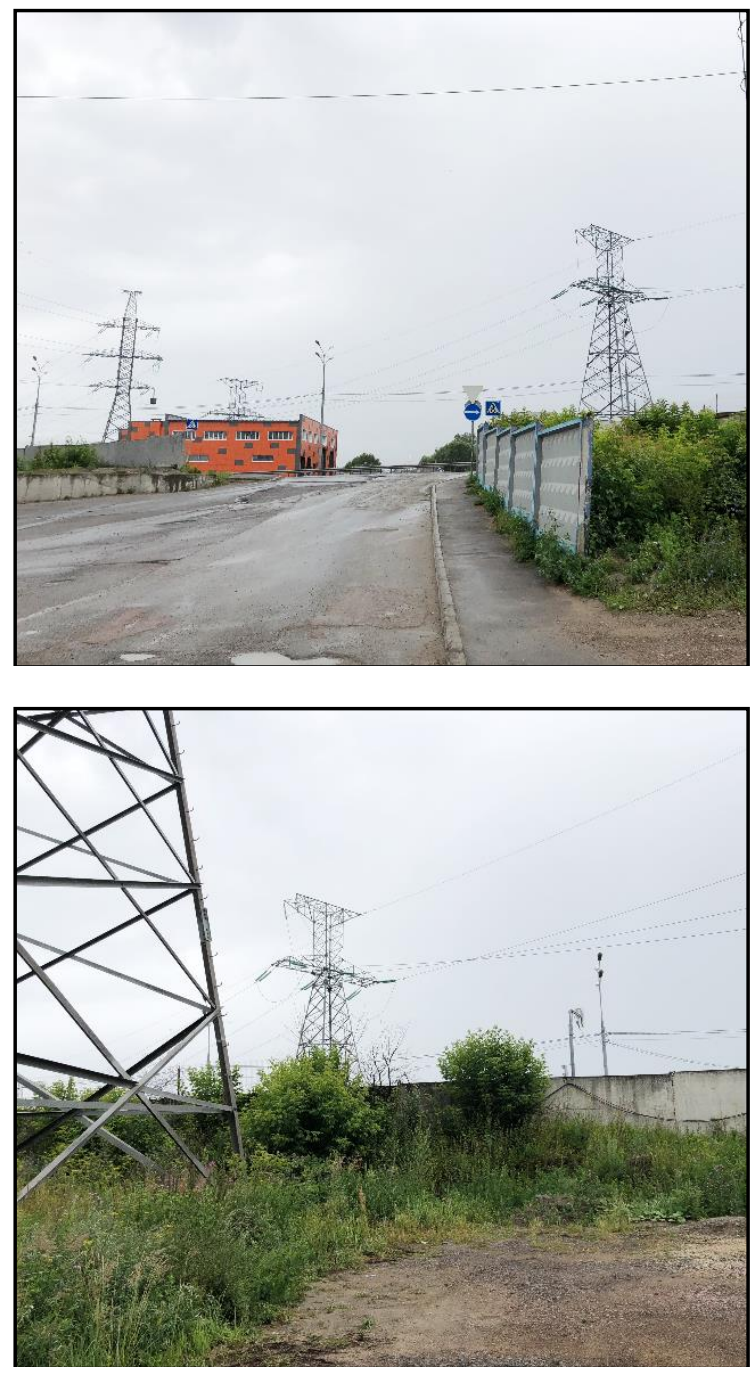

Fig. 1. Photos of the territory under study. 


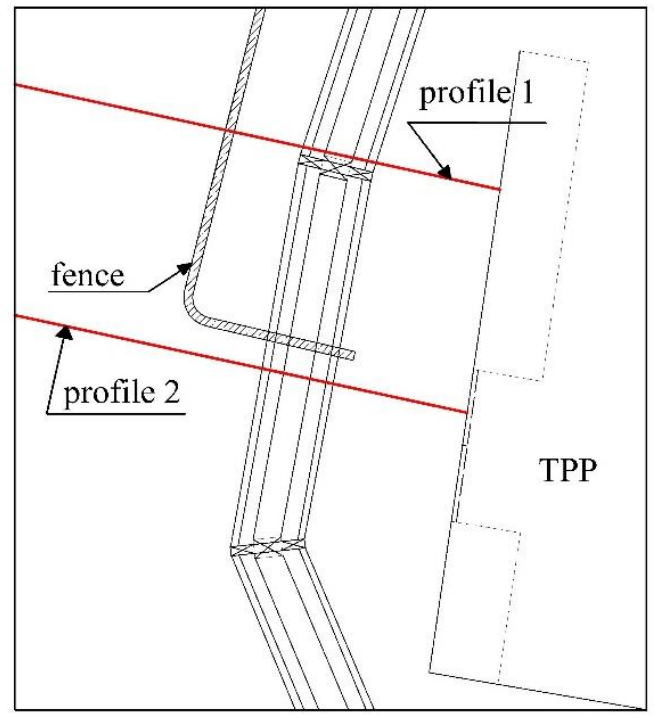

Fig. 2. EMF profiles measurement layout on the area under study.

The surrounding area of TPP-27, located on the edge of Mytishchi city of the Moscow Region was chosen to study the shielding effect of the reinforced concrete fences. The photos of the territory are given in Figure 1. A $220 \mathrm{kV}$ high voltage power transmission line passes (see Figure 2) through the area where the EMF measurements were taken. The measurements were taken on two parallel profiles perpendicular to the axis of the power line communication (PLC). One of them (profile 1) passes through the reinforced concrete fence $2 \mathrm{~m}$ high, the other one (profile 2) - passes by it.

The obtained data were compared with the measurement errors of the electric and magnetic components of the EMF, as determined in the paper [2] in order to asses the study reliability.

\section{Results and discussion}

The measurements were taken with an interval of $2 \mathrm{~m}$ on each profile of Figure 2 . Measurements of electric and magnetic field intensity results diagrams are given in Figure 3 and Figure 4 respectively.

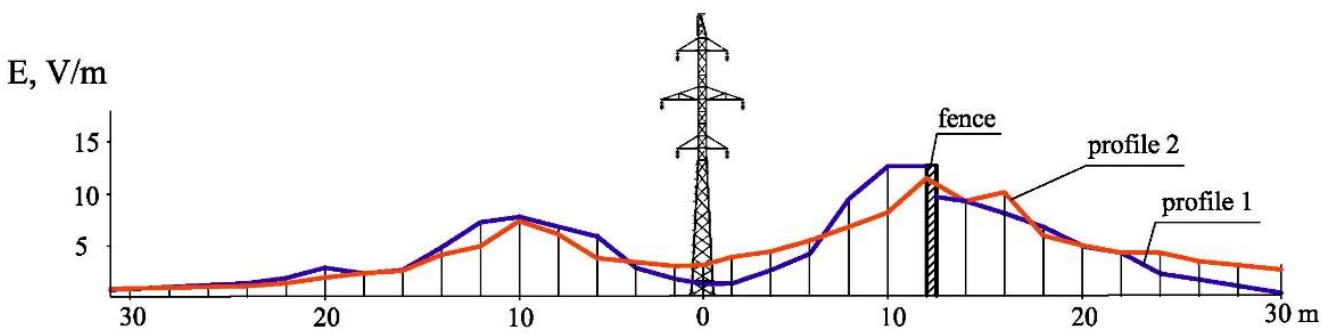

Fig. 3. The EMF electric component intensity. 


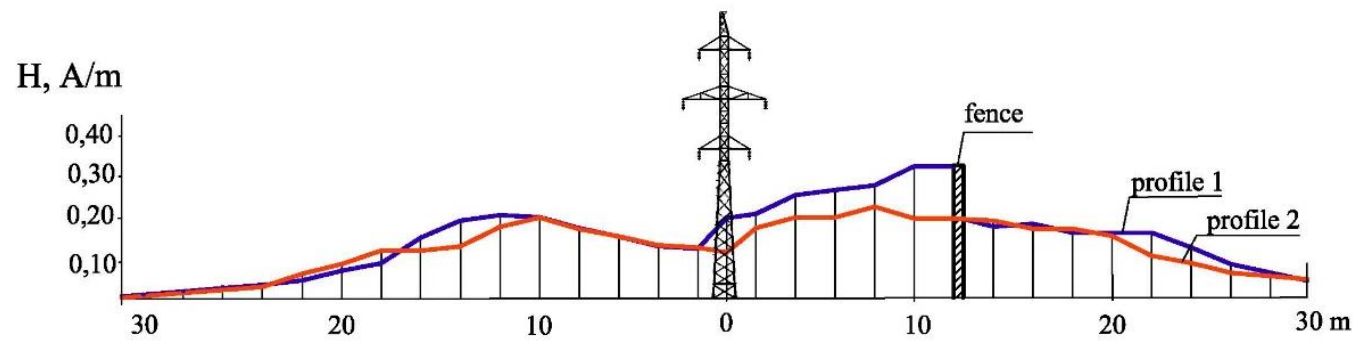

Fig. 4. The EMF magnetic component intensity.

The electric and magnetic components of EMF on profile 2 diagrams passing by the fence show their approximate symmetry with respect to the PLC axis, which is demonstrated for the magnetic component. The imperfect symmetry of the diagrams is due to the fact that profile 2 passes near the fence, which distorts the EMF.

There is a sharp spike of the intensity of both components of the EMF in front of the fence and their steep fall behind it on the diagram relating to profile 1 . These effects are associated with the effect of steel reinforcement inside the fence, in which an alternating electric current is generated at the same frequency as in the high-voltage power line. This current is characterized by a complex configuration and generates its own EMF. The superposition of both EMFs generates a cumulative field that causes the effects of EMF reflection in front of the fence and the EMF shielding behind it. When passing through the fence, the EMF is refracted and part of its energy is absorbed, which causes the EMF attenuation effect. Thus, the partial reflection of the EMF in front of the fence and the attenuation of the EMF within it determine the shielding effect. In the best case scenario, with an infinite conductive wall, the Faraday shield effect would appear, which would be completely screened by the EMF [5].

The shielding effect is practically not manifested (see Figure 3 and 4) at a respectful distance from the fence, where the measuring instrument is in the line of sight from the PLC wires.

Considering the results of the study [2], the measured values of the intensity of the electric and magnetic components of EMF significantly exceed their measurement errors. This circumstance points to measurement validity.

The results obtained in this paper allow us to make useful recommendations for the construction of reinforced concrete fences near residential and industrial buildings, as well as for the work places arrangement in strong EMF areas.

\section{Conclusions}

- A study was conducted to assess the shielding effect of reinforced concrete fences in the EMF of industrial frequency PLC.

- The effects of an abrupt increase in the electric and magnetic EMF components intensity in front of the reinforced concrete fence and its decrease behind the fence are revealed. These effects are associated with the effect of steel reinforcement inside the fence, in which an alternating electric current is generated with the same frequency as in the highvoltage power line. The shielding effect determines the partial reflection of EMF in front of the fence and decrease of EMF inside it. Given that, the reinforced concrete fence has the properties of the Faraday shield. 
- The study validity is established taking into account the comparison of the measurement results with the previously made estimates of the measurements errors of the electric and magnetic components of the EMF.

- Accounting for the shielding effect of reinforced concrete fences provides perspectives of organizing the protection of the population near residential and industrial buildings, as well as protection of personnel working in the strong EMF areas.

\section{References}

1. Guidelines for limiting exposure to time-varying electric and magnetic fields ( $1 \mathrm{~Hz}$ to $100 \mathrm{kHz}$ ), Health Physics, 6, 818-836 (2010)

2. M. Amirkhanyan, F. Bryukhan, MATEC Web of Conferences 170, 02020 (2018)

3. D. Micheli, A. Delfini, F. Santoni, F. Volpini, M. Marchetti, IEEE Antennas and Wireless Propagation Letters, 14, 698-702 (2015)

4. D.E. Pelevin, Electrotechnics and Electromechanics, 4, 53-55 (2015)

5. L.D. Landau, E.M. Lifshits. Electrodynamics of continuous media (Fizmatlit Publishing House, Moscow, 2005) 